\title{
The Source Credibility in Social Media
}

\author{
Theodosia C. Nathalia, Yustisia Kristiana \\ \{heodosia.nathalia@uph.edu
}

Universitas Pelita Harapan, Tangerang, Indonesia

\begin{abstract}
This study will discuss about the importance of Source credibility in social media for Indonesia traveler in planning a vacation. The paper aims to examine the information's credibility sources information on information seeking motive, entertainment motive, relationship maintenance motive and information sharing motive to help the process of making decision in travelling. This research gathered data from 324 Indonesia's traveler that using media social for planning their vacation and analyses using SEM (Structural Equation Modelling). The study revealed that source credibility has a positive and significant effect on the motive for maintaining information sharing and intentions but does not affect the motive for information seeking and entertainment motives. Motivation to seek information positively and significantly affect the intention to provide information. Entertainment motives do not affect the intention to share information. The motive for maintaining relationships has no influence on the purpose of sharing information.
\end{abstract}

Keywords: Source credibility, information seeking motive, entertainment motive, relationship maintenance motive, information sharing intention

\section{Introduction}

The development of communication media as a means of delivering information provides convenience in various ways. One of the media that has a big impact on society with the entry of technology. Technology has a big impact on people's lives. The existence of positive and negative impacts cannot be avoided and again seen from the role of technology itself in each field. For organizations/companies/industries, the role of technology has a lot of positive impacts, from increasing production yields, improving services to increasing corporate revenues (Law, Leung and Buhalis, 2009).

One of the information technologies that are in demand by the public, especially the Indonesian people, is the use of the internet. Internet use in Indonesia reached 132.7 million people or around $50.5 \%$ of the total population of Indonesia which reached 256.2 million. The internet becomes a static media that is in great demand because it can provide information as well as two-way interaction between users in it. Media browsing conducted by internet users, most using mobile devices (smartphones) of 89.9 million or 67.8\% (Asosiasi Penyelenggara Jasa Internet Indonesia, 2017). Furthermore data can be useful for companies that use websites as a communication and information tool in providing responsive services, ease of use, and determination of potential customers.

The Ministry of Communication and Information Technology also recorded 63 million people and $95 \%$ of people use the internet to access social networks. According to data from Webershandwick, a public relations company and communication service provider, for 
Indonesia there are around 65 million active Facebook users and 19.5 million active Twitter users, Path with 700,000 users in Indonesia, Line 10 million users, Google+ 3.4 million users and Linkedlin 1 million users (Kominfo, 2013).

Producers on social networks are people who have produced or produced something in the form of videos and images which then upload them to their social media. Seeing the magnitude of the use of this media, social media can be used by companies or industries in promoting the products and services offered. One industry that uses social media as a promotional tool is the tourism industry.

Rapid development in terms of ordering, providing information through electronic media opens opportunities for the tourism industry to innovate in developing virtual sizes and communicating with tourists (Buhalis, 2000). Even the use of social media can give individuals the freedom to determine and travel to various destinations and tourist attractions (Kotler and Keller, 2015). The ease provided by social media in providing information is also widely used by travelers to share knowledge and experience in traveling. Travel experience is a subjective evaluation of individuals regarding events related to their tourism activities from planning and preparation; during the trip until after the trip in the form of memories (Brent Ritchie, Wing Sun Tung and Ritchie, 2011). Sharing experiences is not only related to destination knowledge (such as prices, tourist attractions, tourist destinations), but can also be through emotional communication, imagination and fantasy about the attraction of the destination in the form of photos, emoticons or languages linguistics which is usually used in communicating online (Baym, 2017). Besides sharing information, tourists use social media to share experiences (Munar and Jacobsen, 2014).

The tourism industry uses social media as a form of marketing by introducing tourist destinations either through official sites or through travelers who have visited destinations and tourist attractions. For the tourism industry, the usefulness of technology is very influential on income figures, operational efficiency to the marketing media to the public (Law, Leung and Buhalis, 2009). As for tourists, the benefits obtained in the form of good service quality, more experience, up to attractive price variations (Toh, DeKay and Raven, 2011). In an effort to achieve the objectives of tourism, the message characteristics given to information technology media play a role in shaping trust in the information provided (Yi et al., 2013). Therefore, the accuracy of information from trusted sources along with accurate data that is useful to provide an understanding of behavioral changes and beliefs about information received (Bhattacherjee and Sanford, 2006).

The proper use of social media through the process of persuasion and the fabric of closeness can increase people's trust in the information received. People will trust the information from the closes one, relatives or someone who has a big influence to other people like community leaders, expert and celebrities (Bandura, 1977) that have many follower in their social account.

A person's popularity becomes an important factor provided the information is stated true or false. A person's popularity can be seen from the number of followers (follower) of the person who then provides feedback from all the information provided, usually in the form of an emoticon and images. Community trust is based on the person's experience and no longer based on official data or sites provided by the government. From the theory of imitation (Bandura, 1977), which states people learn by imitating something from seeing, observing behavior and other experiences and making it as a guide in their behavior. This theory reveals that reliable information is no longer based on sources with knowledge and expertise. One's popularity has an important role as trusted information delivered. This underlies the formation 
of cooperative relationships between industries that intend to market the products and services provided. By using celebrities as brand ambassadors of business brands that are marketed.

The existence of celebrity support is a form of strategy used by companies in marketing a product, where consumers can associate themselves with brand value from the perspective of celebrities they admire (Kotler and Keller, 2015). The tourism industry needs celebrities who are quite famous to be able to help market goals and products offered. The importance of using celebrity support with a good image and very well known to the public (Goldsmith et al., 2006). The importance of using this brand ambassador can be seen from the official website of the Indonesian Ministry of Tourism with 73,838 followers with a total of 73,468 account enthusiasts, following developments in information about destinations and tourist attractions in Indonesia (Ministry of Tourism Facebook account, 2017), while the number of followers for celebrities like Raisa (Indonesian singer), the number of followers more than 15 million and around 500 thousand people (IG Raisa6690, 2017) giving feedback in form as emoticon like or love in all her activities. Other celebrity is Rossa (singer and tourism ambassador of Indonesia's tourism). She has 700 followers that always give comment at her social media account (IG Rossa).

The paper aims to examine the information's credibility sources information on information seeking motive, entertainment motive, relationship maintenance motive and information sharing motive in order to help the process of making decision in travelling.

\section{Literature Review}

\subsection{Source Credibility}

In communicating, it takes interaction of two people or more in the process. Intertwined communication is based on the recipient's trust with the source. Any information can be received if the information comes from a source that has credible credibility. The credibility of sources as sources of information that can be trusted, have competence and can be accepted by recipients of information (Bhattacherjee and Sanford, 2006).

To gain trust in the provision of information, detailed information about the resource person is required which includes a personal identity in full, as well as the competencies they possess. This is an important factor of a person's credibility can be accounted for (Hui et al., 2012). Furthermore, it was revealed that with the credibility component possessed by someone, it would be easier to influence others. If the resource person has good credibility in their field, then the recipient will be easy to be persuaded (Hovland, 2007).

\subsection{Information Seeking Motive}

Human needs to get information, have been positively helped by information systems developed by technology. This technological advancement makes media service users to search as much data as possible in a short time. A person's behaviour towards searching online in the process of trip planning can even give more time to explore his choices before deciding (Jordan, Norman and Vogt, 2013). In using online search, the user will still focus on the quality of the information obtained. This again refers to the quality of the argument and credibility of the source in the information provider. The same way that online informationseeking behaviour has been made previously as a process involving the assessment of information quality (Rieh, 2002). 
One of the fields most sought after by media users is tourism. Many travelers use online media to find tourist destinations and tourist attractions in an area. The motivation of travelers to use information technology online is that travelers have plenty of time to search, process and utilize tourist information and manage it well (Ho, Lin and Chen, 2012).

\subsection{Entertainment Motive}

The concept of entertainment is defined as an activity that provides pleasure and relaxation (Shrum, 2004). Social media as a source of entertainment can motivate users to use it more often. This happens because when social media is used as a good entertainment medium, it can help reduce a person's stress level (Lee et al., 2010). This is in line with previous research (Papacharissi and Rubin, 2000).

The presence of quality online reviews can make users feel entertained. Users or consumers who get exposure to numbers of photos, videos, reviews, promotions, and/or information can use it to fulfil their free time and become a motive in entertaining themselves (Hur et al., 2017).

\subsection{Relationship Maintenance Motive}

Socialization is used by individuals to establish relationships with other individuals. Various ways are done by the community to be in a community and can interact with each other. Everyone has a different way of doing socialization. There are two types of influence of individuals socializing their environment: (1) the social influence of information and (2) normative social influence. The social influence of information is the influence of receiving information obtained from other people as evidence of the phenomenon or reality that exists, while the normative social influence refers to the influence in adjusting to the expectations of others with the group (Deutsch and Gerard, 1955).

One of the uses of social media is to establish relationships with new people and communicate with friends and relatives. Data refers to maintaining relationships (Sheldon, 2008).

\subsection{Information Sharing Intentions}

The emergence of intention to share according to the theory of cognitive evolution, driven by intrinsic motivation and extrinsic motivation. And the motivation to provide information is influenced by extrinsic motivation, namely motivation that arises not from satisfaction with the content of the activity, but from external rewards received from the community and the resulting behaviour arises from the values derived from the interaction (Hsu and Lin, 2008).

When giving information using social media, travelers not only share knowledge but experience sharing processes. Experiences as subjective evaluations of individuals in undergoing events or events in their tourism activities, starting from before the trip (planning or preparation), during the trip and after the trip or related to memory (Brent Ritchie, Wing Sun Tung and Ritchie, 2011). The intention to provide information is usually done through a community that has the same interests and motivations that will contribute from the information provided. The interaction of discussions with positive and negative impacts would increase the high intensity of use on social media used (Hur et al., 2017).

Based on the literature review, the conceptual model proposed is: 


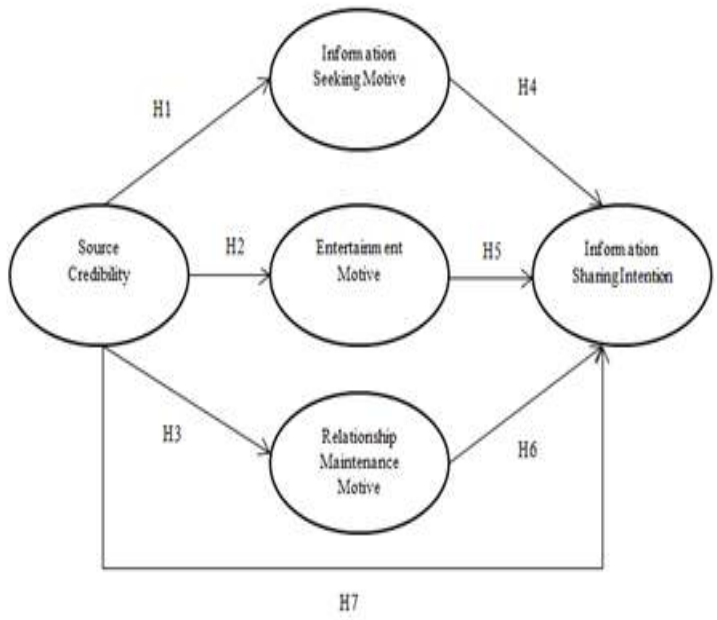

Figure 1. Structural Model

Using the model proposed, the hypotheses are:

H1 : The source credibility has a positive impact to information seeking motive

H2 : The source credibility has a positive impact to entertainment motive

H3 : The source credibility has a positive impact to relationship maintenance motive

H4 : Information seeking motive has a positive impact information sharing intention

H5 : Entertainment motive has a positive impact Information sharing intention

H6 : Relationship maintenance motive has a positive impact information sharing motive

H7 : The source credibility has a positive impact to information sharing intention

\section{$3 \quad$ Methodology}

This research using unit analysis is Indonesia's traveler that using media social to plan, spending and sharing their vacation. According to Statistics Indonesia in 2017, 261 million people lives in Indonesia, this study selected 5 cities with the most populous in Indonesia: Jakarta, Surabaya, Medan, Bekasi and Bandung (Tumoutounews, 2018).

The selected participant as unit must meet all the criteria needed, which are: have a media social and an active user, been to travel more than 1 times, using the social media for sharing the travel experience. Total number of samples selected is 350 respondents because the ideal for analysis of SEM is 200 to 400 participants (Hair et al., 2013). 


\section{$4 \quad$ Finding and Discussion}

\subsection{Respondent Profile}

Demographic data is used to analyse the profile of respondents from social media users. From data processed and analysed 324 questionnaires that distributed to Indonesia Traveler in 5 (five) cities with the most populous population: Jakarta, Surabaya, Medan, Bekasi and Bandung.

Total 350 questionnaires were distributed and only 324 were complete and can be analyzed. Female respondents represent 64 percent $(n=208)$ while the male is 36 percent $(n=116)$. The most of participants were age $<30$ years which amounts to 69 percent $(n=224)$. Meanwhile 27 percent $(n=86)$ of respondents age falls $30-39$ years old; 4 percent $(n=14)$ respondents are age between 40 - 49 years old. The respondents are from domicile in Jakarta with 21 percent $(n=70)$, Bandung with 21 percent $(n=68)$, Bekasi with 21 percent $(n=67)$, Surabaya with 19 percent $(n=61)$ and Medan with 18 percent $(n=58)$ participants. Most respondents are from bachelor's degree 38 percent $(n=124), 34$ percent $(n=108)$ respondents are from high school, others with 18 percent $(n=58)$, master's degree holder 9 percent $(n=30)$, and doctoral degree with 1 percent $(n=4)$. The occupation of the respondents are students with 58 percent $(n=180)$, private employee with 26 percent $(n=86)$, entrepreneur 7 percent $(n=22)$, other 6 percent $(n=18)$, housewife 4 percent $(n=14)$, and civil employee with 1 percent $(n=4)$. Majority of respondents' income were: > IDR 10,000,000 with 52 percent $(n=168)$, income $\leq$ IDR $10,000,000$ - IDR 15,000,000 28 percent $(n=90)$, income $>$ IDR 25,000,000 with 9 percent $(n=28), \leq$ IDR $15,000,000-$ IDR 20,000,000 with 8 percent $(n=28)$ and income rage $\leq$ IDR 20,000,000 - IDR 25,000,000 with 3 percent ( $n=10)$.

The questionnaire also provided information about respondent's profile on social media usage. The result indicates that every respondent in this study have been using social media. The most frequency usage was 88 percent $(n=284)$ respondent use it more than 1 time per day, 8 percent $(n=28)$ use more than 5 times per week and 4 percent $(n=12)$ respondent use $2-4$ times a week. The primary usage, the most usage of social media is for reminiscence travel were 59 percent $(n=192)$, and for organizing usage were 27 percent $(n=86)$, taking travel stage were 14 percent $(n=46)$ respondent. For the primary usage of social media, the majority use Instagram 74 percent ( $n=238)$, Facebook for 21 percent $(n=68)$, other like blog, YouTube, for 2 percent $(n=6)$ and Twitter, Path, LinkedIn only 1 percent $(n=4)$ respondent.

\subsection{Descriptive Statistics}

From the data analysis, the summary of descriptive statistics describes the measure of central tendency (mean values) of each indicator. It appears that the values cluster around is at point three and four (slightly and agree) on the instrument scale. Standard deviation value below 1.00 means that instrument indicating that most of the respondents have a positive perception and relatively consistent regarding the source credibility, information seeking motive, entertainment motive and information sharing intention.

\subsection{Hypotheses Testing}

The hypotheses testing with significance level, below is the hypotheses.

Hypotheses 1, source credibility has a positive but not significant influence on information seeking motive. Traveler will continuing seeks all the information for consideration purpose. 
This is in line with the previous research which describes the credibility of sources not having a large influence on users in making decisions (Mack, Blose and Pan, 2008). However, social media users will continue to use the media in searching for the information needed.

Result for hypotheses 2 with empirical data shown that source credibility has no impact in influence motive of entertainment. This is shown that social media user with motive of entertainment only used social media for passing time, entertaining and a short get away from routine activities. User does not need the credibility of the source. This proves that the reason the traveler uses social media as entertainment is only as a medium of pleasure in eliminating boredom and filling free time (Lee et al., 2010).

Hypotheses 3, the source credibility has a positive influence on relation maintenance. When using social media, the traveler directly shares personal information about them to establish relationships with friends, family and relatives and travel information obtained from social media can be justified. This shows that content from social media is provided by trusted sources which have the ability, skills and knowledge in the information provided. This supports previous research who states that with source credibility, individuals have high trust in the community (McLaughlin, 2016).

Hypotheses 4, information seeking motive has a positive influence on information sharing intention. When traveler found useful information while searching destination or planning vacation, they tend to share that information because they feel they help other traveler with complete information or considering choices. The results of this study are consistent with the statement that the intensity of social media users in the process of finding information that generates user satisfaction will provide reciprocal output by giving information to other users (Munar and Jacobsen, 2014)

Hypotheses 5, entertainment motive has a negative impact to information sharing intention. The motive of entertainment, some user will share information using picture, video, or other entertain items. But only $9 \%$ user want to share it. This does not support previous research which suggests that providing information with hedonic motivation (entertainment) will provide information in the form of images, videos, emoji to the community or groups that can lead to attachment and use of social media in more detail (Park, Kee and Valenzuela, 2009).

Hypotheses 6, relation maintenance motive has negative impact to information sharing intention. Traveler only read or search information from any digital information and people's experiences. They do not contact the person regarding the content of the information or giving opinion on it. This is not in line with research which states that an active increase in an online community has a positive impact on the sense of belonging and an increase in information sharing intentions (Qu and Lee, 2011).

Hypotheses 7 , the source credibility has a positive influence on information sharing intention. Trusted source is making people use the information because they believe that source have the knowledge and expertise about the destination. So, they will share the information at their social media. The results of this study are supported by the results of previous studies which explains information sharing based on the knowledge and expertise of information sources (Munar and Jacobsen, 2014).

\section{Conclusions}

From the discussion and data analysis the conclusions of this study are source credibility has a positive and significant effect on the motive for maintaining information sharing and 
intentions but does not affect the motive for information seeking and entertainment motives. Motivation to seek information positively and significantly affect the intention to provide information. Entertainment motives do not affect the intention to share information. The motive for maintaining relationships has no influence on the purpose of sharing information.

Referring to the findings of the research results, managerial implications that can be recommended are:

1. Tourism professionals participate and contribute to various tourism forums and socialize the use of social media entirely as a medium used to introduce tourist destinations, especially in Indonesia; held regular meetings between associations or organizations for discussing and finding solutions and actions that can be done for the advancement of tourism in Indonesia.

2. This study explains the needs of social media user regarding the content of information in their website. Entrepreneurs should make their websites attractive, informative and complete in each content provided to reduce marketing costs to increase business income. From the results of the study, found the high number of Instagram and Facebook social media usage, so that these two media can be used by business people in promoting the business offered.

3. Ministry of Tourism should develop, promote and update all content on official tourism sites, and using social media as an effective promotional media that can attract domestic and foreign tourists. Ministry of Tourism also can hire a brand ambassador, who has a positive influence on the community, so it can increase the public interest in tourist destinations.

4. The existence of ongoing cooperation from stakeholders in the tourism sector; academic, business actors, communities, government and the media to develop tourism in Indonesia.

\section{REFERENCES}

1. Asosiasi Penyelenggara Jasa Internet Indonesia (2017) 'Penetrasi \& Perilaku Pengguna Internet Indonesia 2017', Penetrasi dan Perilaku Pengguna Internet Indonesia. doi: 10.1542/peds.2011-0218.

2. Bandura, A. (1977) 'Social-Learning Theory Of Identificatory Processes', Handbook of Socialization Theory and Research. doi: 10.1080/19371918.2011.591629.

3. Baym, N. (2017) Personal connections in the digital age, Consumption Markets \& Culture. doi: 10.1080/10714421.2011.573442.

4. Bhattacherjee and Sanford (2006) 'Influence Processes for Information Technology Acceptance: An Elaboration Likelihood Model', MIS Quarterly. doi: 10.2307/25148755.

5. Brent Ritchie, J. R., Wing Sun Tung, V. and Ritchie, R. J. b. (2011) 'Tourism experience management research: Emergence, evolution and future directions', International Journal of Contemporary Hospitality Management. doi: 10.1108/09596111111129968.

6. Buhalis, D. (2000) 'Marketing the competitive destination of the future', Tourism Management. doi: 10.1016/S0261-5177(99)00095-3.

7. Deutsch, M. and Gerard, H. B. (1955) 'A study of normative and informational social influences upon individual judgment', Journal of Abnormal and Social Psychology. doi: $10.1037 / \mathrm{h} 0046408$.

8. Goldsmith, M. I. et al. (2006) 'A developmental transition in growth control during zebrafish caudal fin development', Developmental Biology. doi: 
10.1016/j.ydbio.2006.06.010.

9. Hair, J. et al. (2013) Multivariate Data Analysis: Pearson New International Edition, Prentice-Hall, Inc. doi: 10.1038/259433b0.

10. Ho, C. I., Lin, M. H. and Chen, H. M. (2012) 'Web users' behavioural patterns of tourism information search: From online to offline', Tourism Management. doi: 10.1016/j.tourman.2012.01.016.

11. Hovland, I. (2007) Making a difference: $M \& E$ of policy research. London.

12. Hsu, C. L. and Lin, J. C. C. (2008) 'Acceptance of blog usage: The roles of technology acceptance, social influence and knowledge sharing motivation', Information and Management. doi: 10.1016/j.im.2007.11.001.

13. Hui, A. et al. (2012) 'Lifestyle intervention on diet and exercise reduced excessive gestational weight gain in pregnant women under a randomised controlled trial', BJOG: An International Journal of Obstetrics and Gynaecology. doi: 10.1111/j.14710528.2011.03184.x.

14. Hur, K. et al. (2017) 'An exploration of the factors influencing social media continuance usage and information sharing intentions among Korean travellers', Tourism Management. doi: 10.1016/j.tourman.2017.06.013.

15. Jordan, E. J., Norman, W. C. and Vogt, C. A. (2013) 'A cross-cultural comparison of online travel information search behaviors', Tourism Management Perspectives. doi: 10.1016/j.tmp.2012.11.002.

16. Kominfo (2013) 'Kominfo: Pengguna Internet di Indonesia 63 Juta Orang', Website Resmi Kementerian Komunikasi dan Informatika RI.

17. Kotler, P. and Keller, K. L. (2015) Marketing Management 15/e, Prentice Hall. doi: $10.1177 / 1060028014534195$.

18. Law, R., Leung, R. and Buhalis, D. (2009) 'Information technology applications in hospitality and tourism: A review of publications from 2005 to 2007', Journal of Travel and Tourism Marketing. doi: 10.1080/10548400903163160.

19. Lee, C. S. et al. (2010) 'Indagator: Investigating perceived gratifications of an application that blends mobile content sharing with gameplay', Journal of the American Society for Information Science and Technology. doi: 10.1002/asi.21305.

20. Mack, R. W., Blose, J. E. and Pan, B. (2008) 'Believe it or not: Credibility of blogs in tourism', Journal of Vacation Marketing. doi: 10.1177/1356766707087521.

21. McLaughlin, C. (2016) 'Source Credibility and Consumers' Responses to Marketer Involvement in Facebook Brand Communities: What Causes Consumers to Engage?', Journal of Interactive Advertising. doi: 10.1080/15252019.2016.1223571.

22. Munar, A. M. and Jacobsen, J. K. S. (2014) 'Motivations for sharing tourism experiences through social media', Tourism Management. doi: 10.1016/j.tourman.2014.01.012.

23. Papacharissi, Z. and Rubin, A. M. (2000) 'Predictors of internet use', Journal of Broadcasting and Electronic Media. doi: 10.1207/s15506878jobem4402_2.

24. Park, N., Kee, K. F. and Valenzuela, S. (2009) 'Being Immersed in Social Networking Environment: Facebook Groups, Uses and Gratifications, and Social Outcomes', CyberPsychology \& Behavior. doi: 10.1089/cpb.2009.0003.

25. Qu, H. and Lee, H. (2011) 'Travelers' social identification and membership behaviors in online travel community', Tourism Management. doi: 10.1016/j.tourman.2010.12.002.

26. Rieh, S. Y. (2002) 'Judgment of information quality and cognitive authority in the Web', Journal of the American Society for Information Science and Technology. doi: 10.1002/asi.10017.

27. Sheldon, P. (2008) 'Student favorite: Facebook and motives for its use', Southwestern 
Mass Communication .... doi: 10.1080/03634520216511.

28. Shrum, L. J. (2004) 'Magnitude of Effects of Television Viewing on Social Perceptions Vary as a Function of Data Collection Method: Implications for Psychological Processes', Advances in Consumer Research, 31, pp. 511-513.

29. Toh, R. S., DeKay, C. F. and Raven, P. (2011) 'Travel planning: Searching for and booking hotels on the internet', Cornell Hospitality Quarterly. doi: $10.1177 / 1938965511418779$.

30. Tumoutounews (2018) 'Jumlah Penduduk Indonesia Tahun 2018', tumoutounews.

31. Yi, M. Y. et al. (2013) 'Untangling the antecedents of initial trust in Web-based health information: The roles of argument quality, source expertise, and user perceptions of information quality and risk', Decision Support Systems. doi: 10.1016/j.dss.2013.01.029. 